\title{
Relationship of Demographic Profile of Dairy Farmers with Transitional Diseases in Punjab, India
}

\author{
Niharika Thakur, Parminder Singh", Bharti Deshmukh and Rajesh Kasrija \\ Department of Veterinary and Animal Husbandry Extension Education, Guru Angad Dev \\ Veterinary and Animal Sciences University (GADVASU), Ludhiana, Punjab, India \\ *Corresponding author
}

\section{A B S T R A C T}

The present study was conducted in different districts of Punjab. 250 respondents were

Keywords

Dairy, Education,

Punjab, Training,

Transitional period

Article Info

Accepted:

17 July 2018

Available Online:

10 August 2018 randomly selected and were interviewed personally the help of pretested interview schedule. Most of the farmers were middle aged and young. The education level of most of the farmers was more than high school. Most of the dairy farmers $(52 \%)$ were medium dairy farmers followed by small dairy farmers $(28 \%)$, large dairy farmers $(12 \%)$ and very large dairy farmers $(8 \%)$. Herd Size had a significant difference $(\mathrm{P}<0.05)$ on incidence of diseases like mastitis, ketosis and milk fever. It was found that medium farms (10-29) were significantly $(\mathrm{P}<0.05)$ affected by incidence of diseases like mastitis, ketosis and milk fever. Incidence of metritis $(30.36 \%)$ was found to be less for farmers who undertook training, indicating the significant relationship $(\mathrm{P}<0.05)$ between training and metritis occurrence. Education vary significantly with control of mastitis and metritis $(\mathrm{P}<0.05)$, indicating its role in control of mastitis and metritis. So, this study focuses on role of training and education in enhancing awareness level of dairy farmers about control of various transitional diseases.

\section{Introduction}

Punjab is one of the leading states in dairying and milk production, producing 11.28 Million tonnes of milk, of the total milk production of country which is 165.4 Million Tonnes (National Dairy Development report, 201617). The enhancement in milk production of dairy animals is directly related with good reproductive efficiency (Emanuelson and Oltenacut 1998) and the success of dairy farming lies in ensuring proper and optimal reproductive rhythm of an individual animal in the herd (Agarwal et al., 2005). Economic viability of a dairy venture depends upon reproductive efficiency of its herd. The transition period of a dairy animal (last three weeks before parturition to three weeks after parturition) is of utmost importance as there are tremendous metabolic and endocrine adjustments that the cows must experience from late gestation to early lactation (Grummer, 1995). During transition period, the animal is prone to various diseases such as Milk fever, Ketosis, Retained placenta, Anestrous, Dystokia, Metritis, Mastitisetc. One transition disease may trigger another transitional disease in animals. The 
reproductive disorders such as anoestrus, metritis leads to lesser calves, decreased milk production, long service period and increase in intercalving interval, thereby causing economic losses, leading to infertility and increasing culling rate of animals. So, present study was planned to know about incidence of transitional diseases and relationship of demographic profile with transitional diseases in Punjab.

\section{Materials and Methods}

The present study was conducted on 250 randomly selected dairy farmers from different districts of Punjab. Dairy farmers were personally interviewed with the help of pretested interview schedule. The demographic profile parameters of dairy farmers such as age, education, herd size and any training were also noted. The data was tabulated and put to suitable statistical analysis with the help of SAS 9.3 system Carry N C, USA.

\section{Results and Discussion}

It is clear from Table 1 that most (40\%) of the dairy farmers belonged to middle age group (34-46 years), followed by $30.8 \%$ to young age group $(<34$ years $)$ and $29.2 \%$ to old age group. Rajput et al., (2012) also reported that majority of dairy farmers belonged to middle age group followed by young and old age groups. The education level of most of the farmers is more than high school. Parmar (2014) also reported that farmers are becoming educated with changing times and are trying to enhance their knowledge level. Most of the dairy farmers (52\%) were medium dairy farmers followed by small dairy farmers $(28 \%)$, large dairy farmers $(12 \%)$ and very large dairy farmers $(8 \%)$. However, Kaur (2006) found $45.5 \%$ farmers had small herd strength (4-10). It means with passage of time the herd size of farmers' is also growing.
Since per unit income is not increasing only alternative is bigger the farm size, more is the income. It means livestock is still in phase of development. 58\% respondents did not undertake any training. Similarly, Laldinpuii (2013) also reported that majority (67.6\%) farmers did not attend any training on dairy farming. It may be due to the reason that farmers are not having any awareness regarding curriculum of training programmes.

\section{Incidence of transitional diseases}

Figure 1 clearly indicate that highest incidence was found to be of anoestrus (59.6\%) followed by mastitis (52\%), retention of placenta (38\%), metritis (22.4\%), milk fever (18\%), dystokia (14.8\%) and ketosis (10.4\%). Kasrija (2016) reported similar incidence of anoestrus in dairy farms of sub mountain undulating region of Punjab. The farmers did not provide proper nutrition during the dry period and even duration of dry period was short. This resulted in negative energy in animals and animals failed to ovulate. Mir et al., 2015 reported that incidence of mastitis was high due to lack of managemental practices viz hygiene practices related to milking.

Table 2 indicates that age and education of dairy farmer had no significance effect on occurrence of transitional diseases. Herd Size had a significant difference $(\mathrm{P}<0.05)$ with incidence of diseases like mastitis, ketosis and milk fever. It was found that medium farms $(10-29)$ were significantly $(\mathrm{P}<0.05)$ affected by incidence of diseases like mastitis, ketosis and milk fever. Incidence of diseases like mastitis, ketosis and milk fever were more common in medium farms because of lack of management and hygiene practices leading to mastitis, and occurrence of milk fever and ketosis are due to lack of proper nutritive modifications and improper Dietary cationicanionic difference (DCAD) during transition period. 
Fig.1 Percentage of incidence of transitional diseases

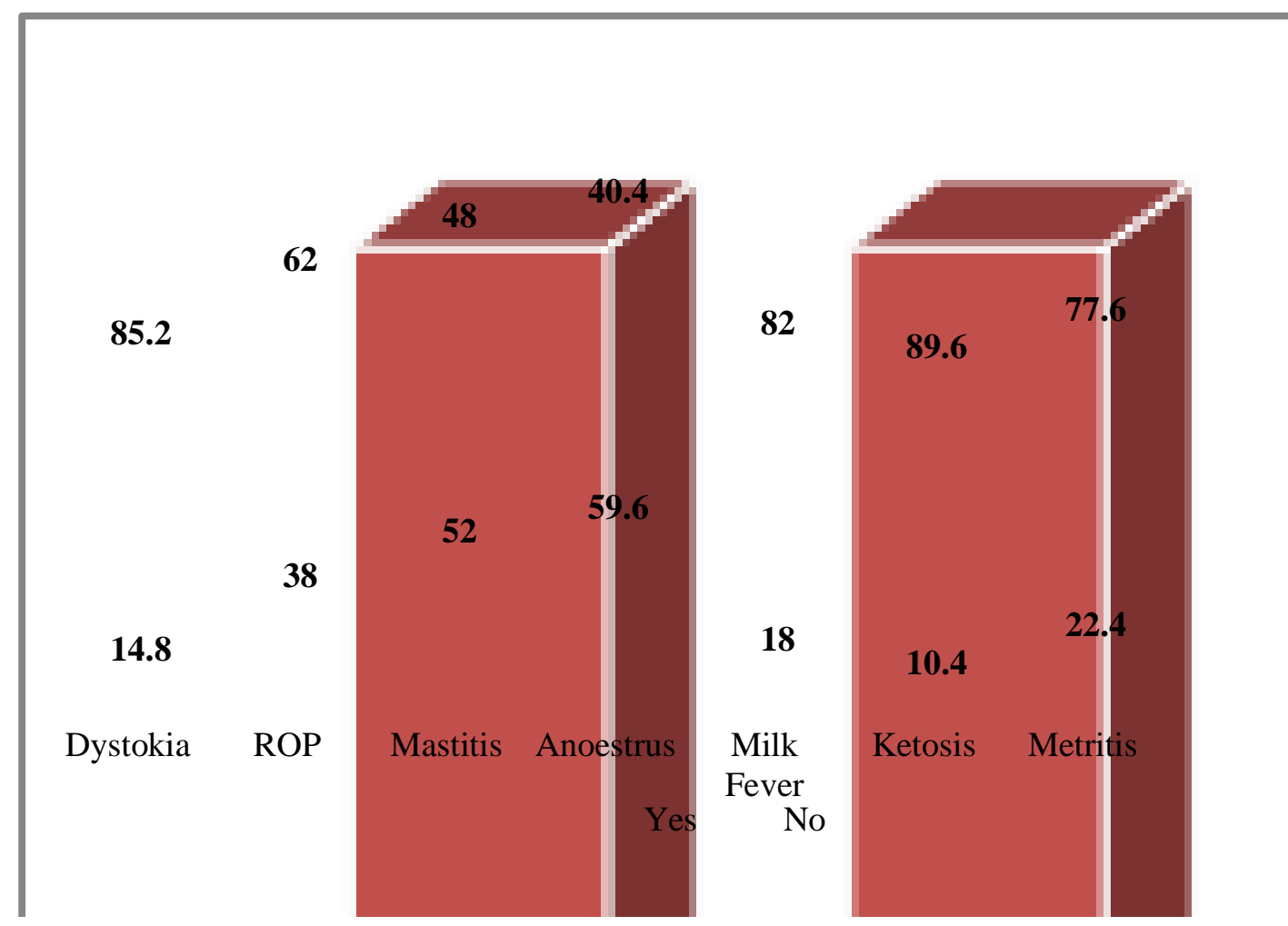

Table.1 Distribution of dairy farmers with respect to demographic profile

\begin{tabular}{|c|c|c|c|}
\hline Parameters $(n=250)$ & Category & Frequency & Percentage \\
\hline \multirow{3}{*}{ Age(in years) } & Young $(<34)$ & 77 & 30.80 \\
\hline & Middle (34 - 46) & 100 & 40.00 \\
\hline & Aged $(>46)$ & 73 & 29.20 \\
\hline \multirow{6}{*}{ Education } & Illiterate & 12 & 4.80 \\
\hline & Primary & 13 & 5.20 \\
\hline & Middle & 10 & 4.00 \\
\hline & High School & 76 & 30.40 \\
\hline & Higher Secondary & 59 & 23.60 \\
\hline & Graduate and above & 80 & 32.00 \\
\hline \multirow{4}{*}{ Herd Size } & Small $(<10)$ & 70 & 28.00 \\
\hline & Medium (10-29) & 130 & 52.00 \\
\hline & Large (30-49) & 30 & 12.00 \\
\hline & Very large $(\geq 50)$ & 20 & 8.00 \\
\hline \multirow[t]{2}{*}{ Training } & Yes & 105 & 42.00 \\
\hline & No & 145 & 58.00 \\
\hline
\end{tabular}


Table.2 Relationship of demographic profile with incidence of various transitional diseases

\begin{tabular}{|c|c|c|c|c|c|c|c|c|}
\hline $\begin{array}{l}\text { Parameter } \\
(\mathrm{n}=\mathbf{2 5 0})\end{array}$ & Category & Dystokia & ROP & Mastitis & Anoestrus & Milk Fever & Ketosis & Metritis \\
\hline \multirow[t]{4}{*}{$\begin{array}{l}\text { Age } \\
\text { (Years) }\end{array}$} & $\begin{array}{l}\text { Young } \\
(<34)\end{array}$ & $11(29.73)$ & $28(29.47)$ & $34(26.15)$ & $43(28.86)$ & $13(28.89)$ & $2(26.92)$ & $14(25.00)$ \\
\hline & $\begin{array}{l}\text { Middle (34 } \\
46)\end{array}$ & $17(45.95)$ & $37(38.95)$ & $58(44.62)$ & $56(37.58)$ & $21(46.67)$ & $12(46.15)$ & $24(42.86)$ \\
\hline & Old $(>46)$ & $9(24.32)$ & $30(31.58)$ & $38(29.23)$ & $50(33.56)$ & $11(24.44)$ & $7(26.92)$ & $18(32.14)$ \\
\hline & Overall & $37(14.80)$ & $95(38.00)$ & $130(52.00)$ & $149(59.60)$ & $45(18.00)$ & $26(10.40)$ & $56(22.40)$ \\
\hline \multirow[t]{7}{*}{ Education } & Illiterate & $1(2.70)$ & $6(6.32)$ & $6(4.62)$ & $5(3.36)$ & $1(2.22)$ & $0(0.00)$ & $2(3.57)$ \\
\hline & Primary & $2(5.41)$ & $6(6.32)$ & $6(4.62)$ & $9(6.04)$ & $2(4.44)$ & $2(7.69)$ & $4(7.14)$ \\
\hline & Middle & $0(0.00)$ & $3(3.16)$ & $5(3.85)$ & $6(4.03)$ & $2(4.44)$ & $0(0.00)$ & $1(1.79)$ \\
\hline & High School & $12(32.43)$ & $23(24.21)$ & $35(26.92)$ & $53(35.57)$ & $16(35.56)$ & $10(38.46)$ & $22(39.29)$ \\
\hline & $\begin{array}{l}\text { Higher } \\
\text { Secondary }\end{array}$ & $9(24.32)$ & $20(21.05)$ & $29(22.31)$ & $31(20.81)$ & $11(24.44)$ & $5(19.23)$ & $14(25.00)$ \\
\hline & $\begin{array}{l}\text { Graduate } \\
\text { and above }\end{array}$ & $13(35.14)$ & $37(38.95)$ & $49(37.69)$ & $45(30.20)$ & $13(28.89)$ & $9(34.62)$ & $13(23.21)$ \\
\hline & Overall & $37(14.80)$ & $95(38.00)$ & $130(52.00)$ & $149(59.60)$ & $45(18.00)$ & $26(10.40)$ & $56(22.40)$ \\
\hline \multirow{5}{*}{ Herd Size } & Small $(<10)$ & $9(24.32)$ & $32(33.68)$ & $28(21.54)$ & $49(32.89)$ & $9(20.00)$ & $11(42.31)$ & $3(37.50)$ \\
\hline & $\begin{array}{l}\text { Medium } \\
(10-29)\end{array}$ & $18(48.65)$ & $40(42.11)$ & $72(55.38)^{*}$ & $72(48.32)$ & $19(42.22)^{*}$ & $9(34.62)^{*}$ & $5(62.50)$ \\
\hline & $\begin{array}{l}\text { Large (30- } \\
49)\end{array}$ & $5(13.51)$ & $14(14.74)$ & $14(10.77)$ & $19(12.75)$ & $19(42.22)$ & $6(23.08)$ & $0(0.00)$ \\
\hline & $\begin{array}{l}\text { Very large } \\
(\geq 50)\end{array}$ & $5(13.51)$ & $9(9.47)$ & $16(12.31)$ & $9(6.04)$ & $6(13.33)$ & $0(0.00)$ & $0(0.00)$ \\
\hline & Overall & $37(14.80)$ & $95(38.00)$ & $130(52.00)^{*}$ & $149(59.60)$ & $45(18.00)^{*}$ & $26(10.40)^{*}$ & $8(3.20)$ \\
\hline \multirow[t]{3}{*}{ Training } & Yes & $14(37.84)$ & $35(36.84)$ & $54(41.54)$ & $60(40.27)$ & $18(40.00)$ & $17(65.38)$ & $17(30.36)^{*}$ \\
\hline & No & $23(62.16)$ & $60(63.16)$ & $76(58.46)$ & $89(59.73)$ & $27(60.00)$ & $9(34.62)$ & $39(69.64)$ \\
\hline & Overall & $37(14.80)$ & $95(38.00)$ & $130(52.00)$ & $149(59.60)$ & $45(18.00)$ & $26(10.40)$ & $56(22.40)^{*}$ \\
\hline
\end{tabular}

Figure in parenthesis indicates percentage

$(*)=$ Significant at $5 \%(\mathrm{P}<0.05)$

Table.3 Effect of education to control incidence of transitional diseases

\section{Education}

\begin{tabular}{|l|l|l|l|l|l|l|l|l|l|}
$\begin{array}{l}\text { Transitional } \\
\text { diseases } \\
(\mathbf{n = 2 5 0})\end{array}$ & Category & Illiterate & Primary & Middle & Secondary & $\begin{array}{l}\text { Higher } \\
\text { Secondary }\end{array}$ & $\begin{array}{l}\text { Graduate } \\
\text { and above }\end{array}$ & $\begin{array}{l}\text { Overall } \\
(\mathbf{n = 2 5 0})\end{array}$ \\
\hline Mastitis & Nil & $6(4.92)$ & $7(5.74)$ & $5(4.10)$ & $42(34.43)$ & $30(24.59)$ & $32(26.23)$ & $122(48.80)$ \\
& Any medicine & $4(3.70)$ & $5(4.63)$ & $4(3.70)$ & $31(28.70)$ & $24(22.22)$ & $\mathbf{4 0}(\mathbf{3 7 . 0 4})$ & $108(43.20)$ \\
& Veterinarian & $1(5.26)$ & $1(5.26)$ & $1(5.26)$ & $3(15.79)$ & $52(26.32)$ & $8(42.11)$ & $19(7.60)$ & $\mathbf{2 5 . 3 6 *}$ \\
& Teat Dips & $0(0.00)$ & $0(0.00)$ & $0(0.00)$ & $0(0.00)$ & $0(0.00)$ & $1(1.00)$ & $1(0.40)$ \\
\hline \multirow{2}{*}{ Metritis } & Nil & $10(5.18)$ & $9(4.66)$ & $9(4.66)$ & $54(27.98)$ & $44(22.80)$ & $67(34.72)$ & $193(77.20)$ \\
& Antibiotic & $0(0.00)$ & $0(0.00)$ & $0(0.00)$ & $0(0.00)$ & $1(33.33)$ & $2(66.67)$ & $3(1.20)$ \\
& I/U & $2(4.35)$ & $1(2.17)$ & $1(2.17)$ & $19(41.30)$ & $14(30.43)$ & $9(19.57)$ & $46(18.40)$ & $\mathbf{2 8 . 8 6 *}$ \\
& Veterinarian & $0(0.00)$ & $3(37.50)$ & $0(0.00)$ & $3(37.50)$ & $0(0.00)$ & $2(25.00)$ & $8(3.20)$ & \\
\hline
\end{tabular}

Figure in parenthesis indicates percentage

$(*)=$ Significant at $5 \%(\mathrm{P}<0.05)$ 
Table.4 Effect of herd size to control incidence of transitional diseases

\begin{tabular}{|c|c|c|c|c|c|c|}
\hline $\begin{array}{l}\text { Transitional } \\
\text { diseases }(n=250)\end{array}$ & Category & $\begin{array}{l}<10 \\
(\text { Small })\end{array}$ & $\begin{array}{l}\text { 10-29 } \\
\text { (Medium) }\end{array}$ & $\begin{array}{l}30-49 \\
\text { (Large) }\end{array}$ & $\begin{array}{l}\geq \mathbf{5 0} \\
\text { (Very large) }\end{array}$ & $\stackrel{x}{2}^{2}$ \\
\hline \multirow[t]{4}{*}{ Mastitis } & Nil & $43(17.20)$ & $26(10.40)$ & $1(1.43)$ & $0(0.00)$ & \multirow[t]{4}{*}{$17.09^{*}$} \\
\hline & Any Medicine & $58(23.20)^{*}$ & $57(22.80)^{*}$ & $14(5.60)$ & $1(0.40)$ & \\
\hline & Veterinarian & $21(6.80)^{*}$ & $25(9.40)$ & $4(1.36)$ & $0(0.00)$ & \\
\hline & Teat dips & $0(0.00)$ & $0(0.00)$ & $0(0.00)$ & $0(0.00)$ & \\
\hline \multirow[t]{4}{*}{ Milk Fever } & Nil & $61(87.14)$ & $7(10.00)$ & $2(2.86)$ & $0(0.00)$ & \multirow[t]{4}{*}{$18.13^{*}$} \\
\hline & Oral Calcium & $111(85.38)^{*}$ & $14(10.77)$ & $5(3.85)$ & $0(0.00)$ & \\
\hline & Mifex, Mineral Mixture & $19(63.33)^{*}$ & $8(26.67)$ & $2(6.67)$ & $1(3.33)$ & \\
\hline & Veterinarian & $14(70.00)^{*}$ & $3(15.00)$ & $2(10.00)$ & $1(5.00)$ & \\
\hline \multirow[t]{4}{*}{ Metritis } & Nil & $48(68.57)$ & $0(0.00)$ & 19(27.14) & $3(4.29)$ & \multirow[t]{4}{*}{$15.32 *$} \\
\hline & Antibiotic & $106(81.54)^{*}$ & $1(0.77)$ & $18(13.85)$ & $5(3.85)$ & \\
\hline & $\mathrm{I} / \mathrm{U}$ & $26(86.67)^{*}$ & $1(3.33)$ & $3(10.00)$ & $0(0.00)$ & \\
\hline & Veterinarian & $13(65.00)^{*}$ & $1(5.00)$ & $6(30.00)$ & $0(0.00)$ & \\
\hline
\end{tabular}

Figures in parenthesis indicates percentage $(*)=$ Significant at $5 \%(\mathrm{P}<0.05)$

Berge et al., (2014) also revealed that large herd size was associated with lower incidence of ketosis and milk fever as those farms were feeding total mixed ration.

Training was found to be significantly $(\mathrm{P}<0.05)$ associated with occurrence of metritis. Incidence of metritis $(30.36 \%)$ was found to be less for farmers who undertook training. Other transitional diseases were found to be nonsignificant but still the impact of training is that there were less incidence of transitional diseases in the farms. It means that by undertaking training farmers became well versed about the incidence of transitional diseases and took various preventive measures to control the incidence of these diseases. Similarly, Smith and Risco (2005) also revealed that proper training to farmers may help them to identify the sick animal in early stages of disease, thereby allowing routine, reliable treatment methods and swift return of the animal to healthy state.

Effect of education to control incidence of transitional diseases was also studied. Except for mastitis and metritis, control of all other transitional diseases were reported to be non- significantly associated with education. Table 3 depicts that education vary significantly with control of mastitis and metritis $(\mathrm{P}<0.05)$.It means education has a role in control of these mentioned diseases. For control of mastitis it was found that $37.04 \%$ farmers who were graduate and above tried their self-medication and $26 \%$ farmers belonging to secondary education consulted vets. Teat dips were not used much except for $1 \%$ by dairy farmers who were graduates and above. It means that with increase in education the knowledge and awareness of dairy farmers increased, which helped them to take various remedial measures in cases of emergency if necessary. Similarly, Mulligan and Doherty (2008) revealed that significant body of knowledge should exist which allows for optimal management and prevention of various production diseases.

Table 4 shows that effect of herd size to control incidence of transitional diseases was significantly $(\mathrm{P}<0.05)$ associated for control of diseases like mastitis, milk fever, metritis. For control of mastitis small farmers $(23.2 \%)$ were giving self-medication according to their knowledge, while for controlling milk fever $85.38 \%$, $63.33 \%$, small farmers were giving 
oral calcium, mifex and mineral mixture respectively. $70 \%$ small farmers were also consulting Veterinarian for controlling the incidence of transitional diseases. For controlling metritis too small farmers were making more efforts to control its incidence. $81.54 \%$ farmers were giving antibiotic to animals, while, $86.67 \%$ had knowledge about administering of intrauterine treatment. $65 \%$ small farmers were consulting vets to control the incidence. Hence, it can be analysed that small farmers were more vigilant to take care of their animals as their herd size is small, which is easily manageable. Another reason may be that small farmers took training from any organisation or they may be more educated.

The present study highlights the incidence of various transitional diseases at dairy farms. Highest incidence was found to be of anoestrus $(59.6 \%)$ followed by mastitis $(52 \%)$, retention of placenta $(38 \%)$, metritis $(22.4 \%)$, milk fever $(18 \%)$, dystokia $(14.8 \%)$ and ketosis $(10.4 \%)$. The herd size and training to dairy farmer was reported to be significantly $(\mathrm{P}<0.05)$ associated with incidence of transitional diseases. The effect of herd size to control incidence of transitional diseases was significantly $(\mathrm{P}<0.05)$ associated for control of diseases like mastitis, milk fever, metritis. The effect of education had significant impact to control diseases like mastitis and metritis. So, more training programmes and knowledge enrichment drives should be organized for enhancing the awareness level of dairy farmers about various transitional diseases.

\section{References}

Agarwal, S. K., Singh, S. K. and Rajkumar, R. 2005. Reproductive disorders and their management in cattle and buffalo: A review. Indian Journal of Animal Science 75 (7): 858-73.
Berge, A. C. and Vertenten, G. 2014. A field study to determine the prevalence, dairy herd management systems, and fresh cow clinical conditions associated with ketosis in western European dairy herds. Journal of Dairy Science 97(4): 2145-54.

Emanuelson, U. and Oltenacut, P. A. 1998. Incidence and effects of diseases on performance of Swedish dairy herds stratified by production. Journal of Dairy Science 81: 2376-82.

Grummer, R. R. 1995. Impact of changes in organic nutrient metabolism on feeding the transition dairy cow. Journal of Animal Sciences 73: 2820-33.

Kasrija, R. 2016. 'Effectiveness of instructional material designed on the basis of felt needs of the dairy farmers of Punjab regarding common reproductive conditions'. Ph.D. Dissertation, Guru Angad Dev Veterinary and Animal Sciences University, Ludhiana, India.

Laldinpuii, N. 2013. Studies on dairy farming practices followed and training needs of dairy farmers in Punjab. M.V.Sc. Thesis, Guru Angad Dev Veterinary and Animal Sciences University, Ludhiana, India.

Mir, A. Q., Bansal, B. K., Gupta, D. K. 2015.Short term changes in teats following machine with respect to quarter health status in cows. Journal of Animal Research 5(3): 467-71.

Mulligan, F. J. and Doherty, M. L. 2008. Production diseases of the transition cow. The Veterinary Journal 176(1): 3-9.

Parmar, S. S. 2014. Prevalence of common reproductive problems in dairy animals with respect to management practices in different agroclimatic zones of Punjab. M.V.Sc. Thesis, Guru Angad Dev Veterinary and Animal Sciences University, Ludhiana, India.

Smith, B. I. and Risco, C. A. 2005. Management of periparturient disorders in dairy cattle. Veterinary Clinics: Food Animal Practice 21: 503-21.

\section{How to cite this article:}

Niharika Thakur, Parminder Singh, Bharti Deshmukh and Rajesh Kasrija. 2018. Relationship of Demographic Profile of Dairy Farmers with Transitional Diseases in Punjab, India. Int.J.Curr.Microbiol.App.Sci. 7(08): 3032-3037. doi: https://doi.org/10.20546/ijcmas.2018.708.322 